\title{
Molybdenum Complexes as Catalysts for the Oxidation of Cycloalkanes with Molecular Oxygen
}

\author{
Anna Szymańska ${ }^{1}$ - Wojciech Nitek $^{2}$ - Marcin Oszajca ${ }^{2}$ Wiesław Lasocha ${ }^{1,2}$ • \\ Katarzyna Pamin ${ }^{1} \cdot$ Jan Połtowicz $^{1}$
}

Received: 23 January 2016/Accepted: 12 February 2016/Published online: 3 March 2016

(c) The Author(s) 2016. This article is published with open access at Springerlink.com

\begin{abstract}
A group of new polymolybdates was synthesized and tested in the catalytic oxidation of cycloalkanes. Investigated compounds exhibit broad structural diversity including polymolybdates with isolated anionic clusters ( 0 $\mathrm{dim})$, polymeric anions (1-dim), Mo-O layers (2-dim) as well as hexagonal and orthorhombic molybdenum oxides (3-dim). All studied molybdenum complexes were found to be active in the reaction conditions yielding ketones and alcohols as main products. In the case of layered compounds (2-dim), dicarboxylic acid was detected in the mixture of reaction products. The structure of investigated molybdenum compounds was shown to have influence on yields and selectivities of the investigated reactions. Anionic layers separation (in 2-dim materials) as well as type and charge of organic cations present in the compounds are prime examples of structural factors influencing the oxidation reactions efficiencies. On the basis of obtained results and literature reports a mechanism for the oxidation of cycloalkanes by polymolybdates has been proposed.
\end{abstract}

Electronic supplementary material The online version of this article (doi:10.1007/s10562-016-1716-7) contains supplementary material, which is available to authorized users.

Wiesław Łasocha

lasocha@chemia.uj.edu.pl

1 Jerzy Haber Institute of Catalysis and Surface Chemistry PAS, Niezapominajek 8, 30-239 Krakow, Poland

2 Faculty of Chemistry, Jagiellonian University, Ingardena 3, 30-060 Krakow, Poland

\section{Graphical Abstract}

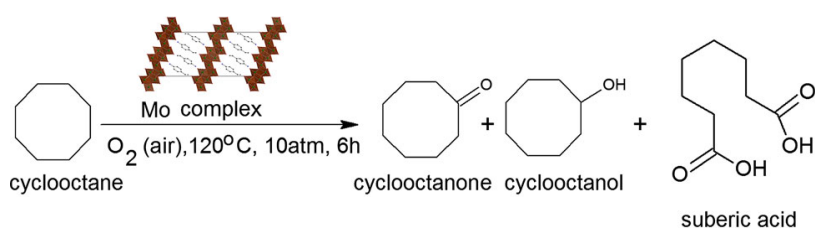

Keywords Cycloalkanes oxidation $\cdot$ Heterogeneous catalysis - Polyoxometalates synthesis - X-ray diffraction · Single crystal $\cdot$ Powder diffraction

\section{Introduction}

Molybdenum complexes are well known as active centers of several enzymes such as oxotransferases [1-4]. Some molybdates show antiviral, antitumoral or antibiotic activity [5-7]. They are also known as efficient catalysts for the oxidation of various organic compounds with different oxygen donors like $\mathrm{ROOH}$ [8-20] and $\mathrm{H}_{2} \mathrm{O}_{2}$ [2129]. Molybdenum(VI) dioxo or oxodiperoxo compounds are commonly encountered in oxidation catalysis. It has been shown that mononuclear peroxo and mono-oxo bridged dinuclear molybdenum complexes are active catalysts for the epoxidation of olefins and nonfunctionalized olefins with t-butylhydroperoxide TBHP as oxygen donor $[8,13-15]$. The epoxidation of olefins catalyzed by a large family of complexes with $\mathrm{MoO}_{2} \mathrm{X}_{2}(\mathrm{~N}-\mathrm{N})_{2}$ or $\mathrm{MoO}_{2} \mathrm{X}_{2}(\mathrm{~N}-$ $\mathrm{O})_{2}$ formula where $\mathrm{N}-\mathrm{N}$ or $\mathrm{N}-\mathrm{O}$ are bidenate ligands and $\mathrm{X}=\mathrm{Cl}, \mathrm{Br}$ or Me has been previously reported $[10,11$, 15, 16]. All these catalysts show high activity and selectivity. 
Molybdenum oxo-peroxo complexes were applied as catalysts for selective oxidation of arylalkyl, diaryl and dialkylsulfides to corresponding sulfoxides with TBHP as oxidant [30-33].

Recent studies have shown that oxo-peroxo molybdenum complexes in combination with $\mathrm{H}_{2} \mathrm{O}_{2}$ can convert a wide range of hydrocarbons like alkanes and alkylbenzenes to the corresponding oxidized products [34]. Molybdenum oxo and oxo-peroxo complexes have been used for selective oxidation of amines [13, 30-33] and for oxidation of allylic alcohols with $\mathrm{H}_{2} \mathrm{O}_{2}$ [34]. Dioxomolybdenum(VI) complexes with a $\mathrm{N}$-salicylidene amino acid hydrazide [28] or oxazoline [16] ligand were applied for oxidation of sulfides with high selectivity to sulfoxides. Dioxomolybdenum(VI) complexes of the $\mathrm{MoO}_{2} \mathrm{~L}_{2}$ type $\left(\mathrm{L}=\left(2^{\prime}\right.\right.$-pirydyl)alcoholate) were used as catalysts for the selective terminal oxidation of $\mathrm{n}$-alkanes with molecular oxygen [35]. The catalytic data indicate an important influence of ligand structure on the catalysts activity and product distribution [35].

Selective catalytic oxidation of cycloalkanes with molecular oxygen is one of the most important and attractive transformations in organic synthesis [36-38]. It is evident that the use of molecular oxygen from air which is an inexpensive, abundant and readily available oxidant in place of other oxygen donors is clearly desirable on economic and environmental grounds.

Very recently, we have reported the synthesis, physicochemical properties and catalytic activity of new oxodiperoxomolybdenum complexes with nicotinic acid in the oxidation of cyclooctane [39].

This paper is a result of combined studies on syntheses of new polymolybdate complexes together with research on their catalytic activity in cycloalkanes oxidation. Catalytic properties are discussed in relation to structural dimensionality of presented polyoxomolybdate complexes, various amounts and types of oxygen atoms (in terms of bonding arrangements) in their structures and ligands used in syntheses.

\section{Experimental}

\subsection{Synthesis and Structural Characterization}

For the purpose of this work, a group of 13 polyoxomolybdenum compounds was selected. Three of them represent compounds with polyoxo moieties in the form of isolated clusters (denoted as $\mathrm{An} ; \mathrm{n}=1,2,3$ ), 4 contain polymeric chains $(\mathrm{Bn})$, we also investigated 4 layered compounds $(\mathrm{Cn})$ and two 'molybdenum oxides'. To determine the influence of structural features on catalytic activity, all selected compounds (except for $\mathrm{MoO}_{3}$ ) are polyoxomolybdates of aromatic amines (three compounds of 4-methylaniline, six compounds of other aniline derivatives, two polyoxomolybdates of 4-methylpyridine). Five of them, namely: A3, B1, B2, B4 and C4 are new compounds, not previously reported. Consult Table 1, for compounds description including chemical formulas, symbols used henceforward and graphical representations of their structures. Crystal structures of investigated catalysts, in particular new compounds, are described in chapter 3.1.

Chemical syntheses of new compounds were carried out in aqueous solutions containing $\mathrm{MoO}_{3}$ or molybdic acid and the appropriate amine. Full description of the syntheses procedures, yields, results of chemical analyzes has been placed in Supporting Information (SI).

The details of X-ray diffraction experiments and results of crystal structure determination are also available in the SI. Crystal structures of A3 and B1 were studied by single crystal methods, other catalysts by 'ab initio' powder diffraction methods. B2 and C4 were investigated with the use of synchrotron radiation while B4 with a laboratory diffractometer. Data concerning structure determination and structure description are listed in Tables SI-1,2,3 (single crystal data) SI-4,5,6,7 (powder data), structures are depicted on accompanying Figs (SI-A3, B1, B2, B4, C4).

While selecting catalysts, thermal stability data for prospective compounds were considered, and if reliable data were not available temperature dependent XRPD studies (in air, temp $=25-600{ }^{\circ} \mathrm{C}$ ) were performed. Results are presented in SI. In general, all compounds were found to be stable in reaction conditions and the most active compounds B1, B3, C2-C4 were stable up to $250{ }^{\circ} \mathrm{C}$.

Excluding samples obtained as large single crystals (A1-A3), surface areas for investigated samples were determined applying BET technique. Results of these experiments are presented in Table 2.

Selected catalysts (B2, C2) after $6 \mathrm{~h}$ of reaction time were recovered by filtration, washed with propanol, dried in air, and reused in catalytic experiments. Obtained results are discussed in chapter 3 (see also Fig. 3).

\section{Catalytic Investigation}

The liquid-phase oxidation of cycloalkanes (cyclopentane, cyclohexane or cyclooctane) was performed in a stainleessteel batch reactor system at the optimum temperature of $393 \mathrm{~K}$ and under the pressure of $10 \mathrm{~atm}$. with the reagents molar ratio $\mathrm{C}_{\mathrm{n}} \mathrm{H}_{2 \mathrm{n}}$ (where $\left.\mathrm{n}=5,6,8\right): \mathrm{O}_{2}=13: 2$. A Teflon-lined reactor of $1 \mathrm{~L}$ volume equipped with a magnetic stirrer was used. In a typical experiment, molybdenum based catalyst having the concentration of $3.3 \times 10^{-4} \mathrm{M}$ 
A. Szymańska et al.
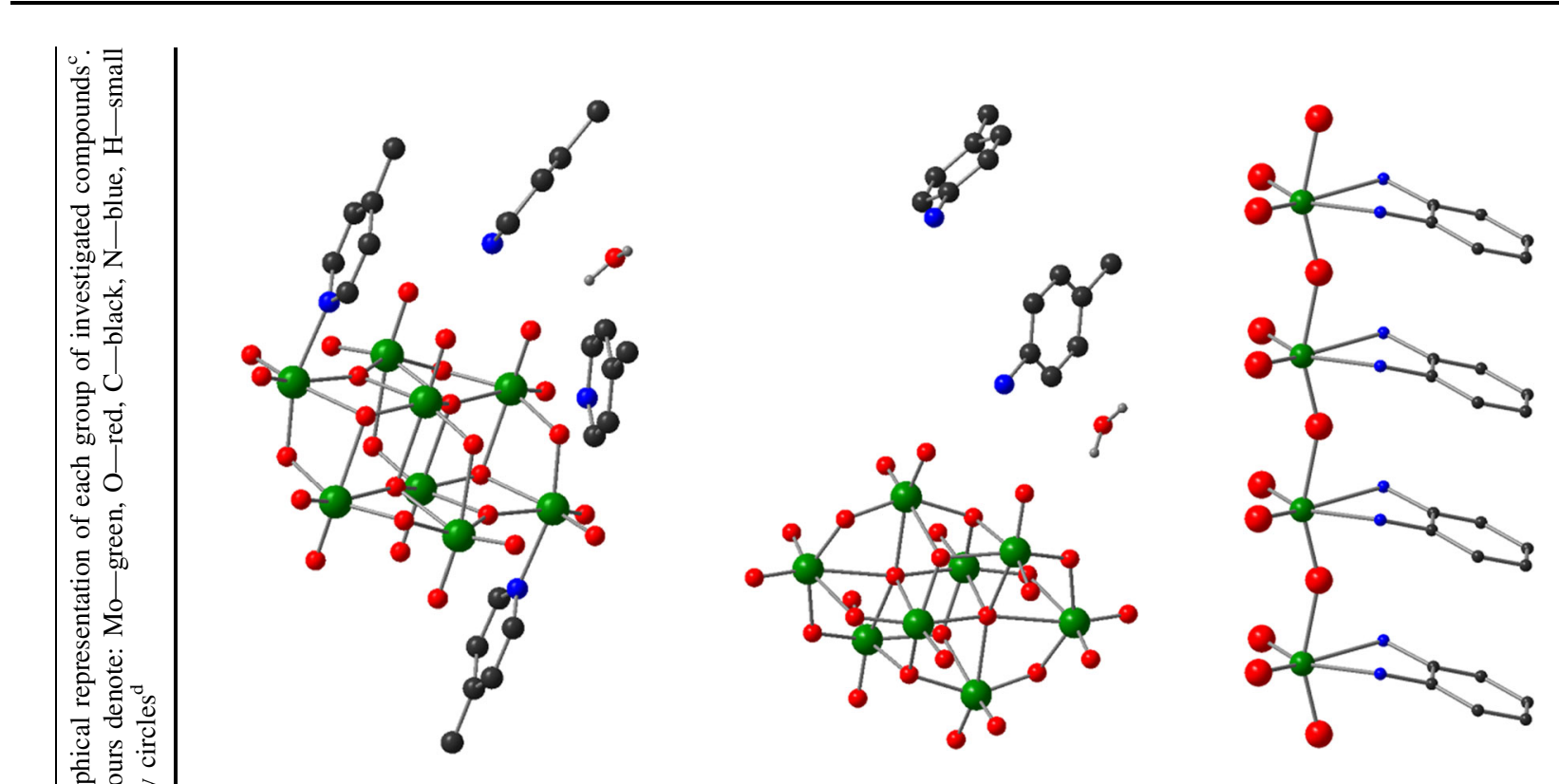

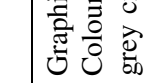
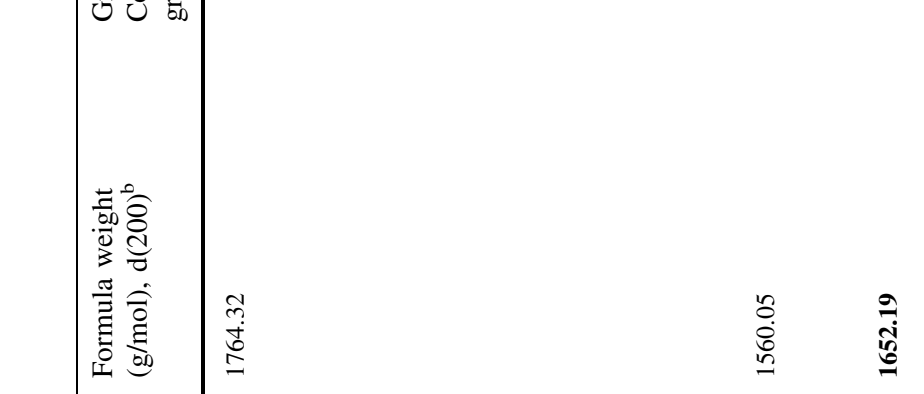

$\infty$
$\stackrel{\text { กิ }}{\text { กิ }}$

홓웅

产

तें

震

$\sum_{0}^{0}$

总

离

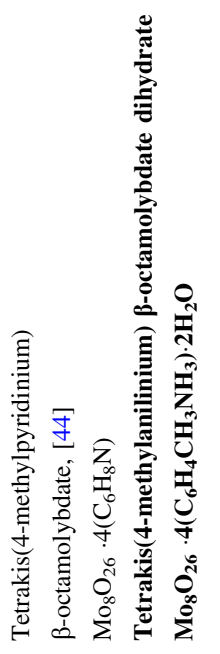




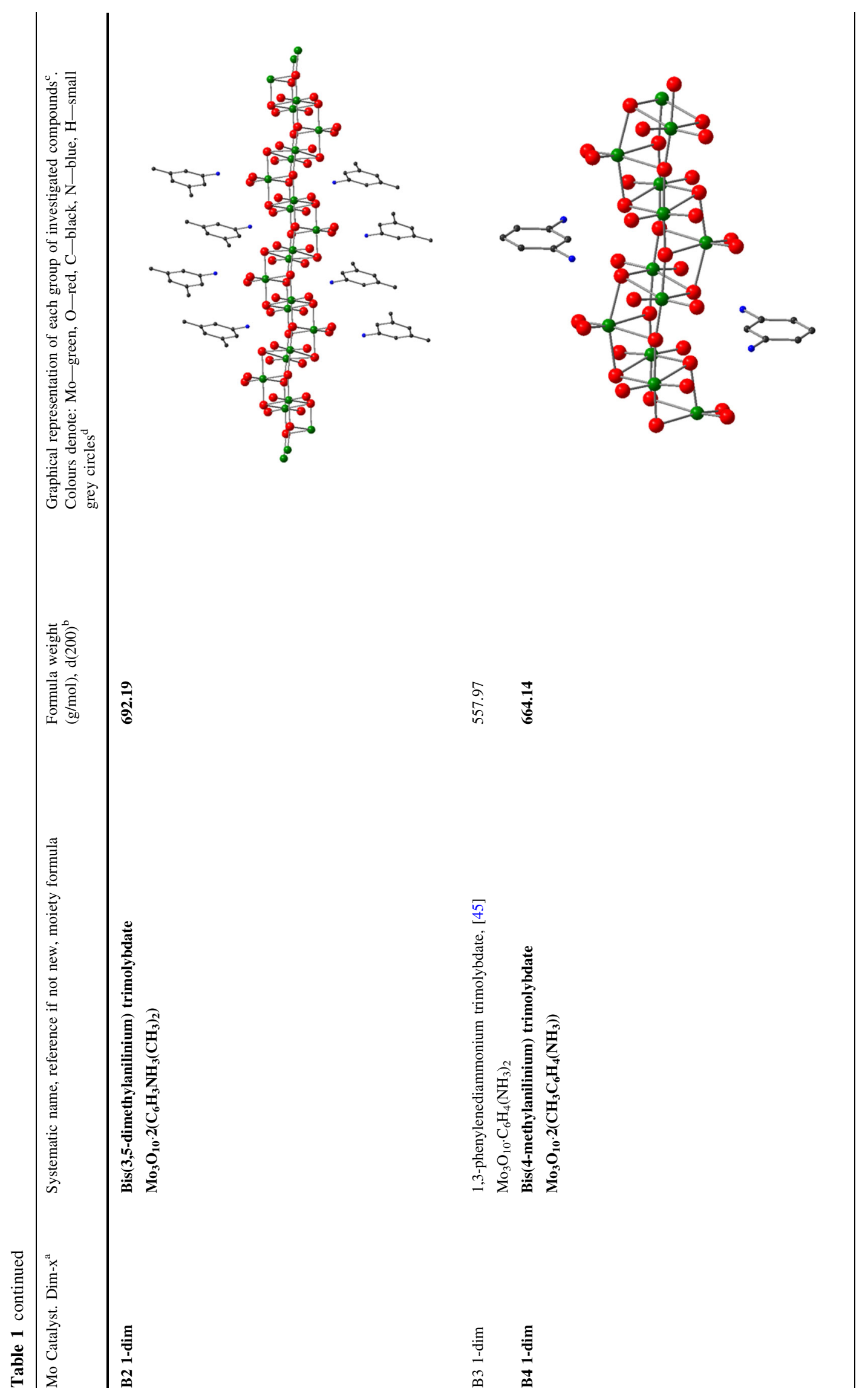




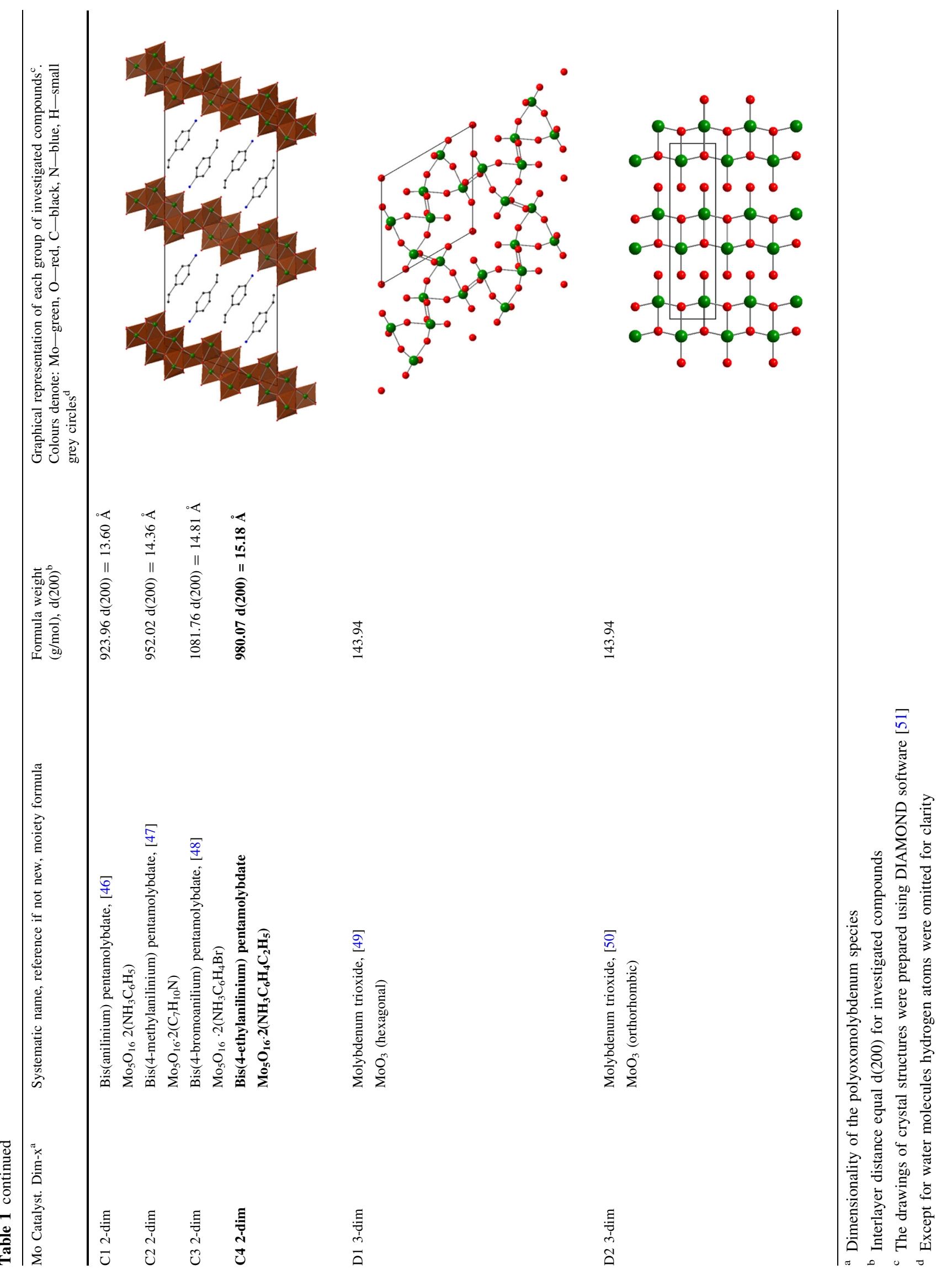


Table 2 Cyclooctane oxidation with molecular oxygen and polyoxomolybdates as catalysts

\begin{tabular}{|c|c|c|c|c|c|c|c|}
\hline \multirow{2}{*}{$\begin{array}{l}\text { Mo catalyst } \\
\text { A1 }\end{array}$} & \multicolumn{2}{|c|}{ Yield of ketone $^{\mathrm{a}}(\%) \mathrm{TON}^{\mathrm{d}}$} & \multicolumn{2}{|c|}{ Yield of alcohol ${ }^{\mathrm{a}}(\%) \mathrm{TON}^{\mathrm{d}}$} & \multirow{2}{*}{$\frac{\text { Ketone }+ \text { alcohol }(\%)}{22.6}$} & \multirow{2}{*}{$\frac{\text { Ketone/alcohol }}{1.4}$} & \multirow[t]{2}{*}{ Surface area $\mathrm{m}^{2} / \mathrm{g}$} \\
\hline & 13.3 & 4990 & 9.3 & 3490 & & & \\
\hline A2 & 10.2 & 3830 & 4.4 & 1650 & 14.6 & 2.3 & \\
\hline A3 & 10.7 & 4010 & 9.4 & 3530 & 20.1 & 1.1 & \\
\hline B1 & 34.3 & 12,860 & 16.6 & 6230 & 50.9 & 2.1 & 4.56 \\
\hline B2 & 29.6 & 11,100 & 15.5 & 5810 & 45.1 & 1.9 & 2.91 \\
\hline $\mathrm{B} 2^{\mathrm{b}}$ & Traces & - & Traces & - & - & - & \\
\hline B3 & 34.7 & 13,010 & 13.6 & 5100 & 48.3 & 2.6 & 12.47 \\
\hline B4 & 25.6 & 9600 & 15.9 & 5960 & 41.5 & 1.6 & 9.59 \\
\hline $\mathrm{C} 1^{\mathrm{c}}$ & 11.7 & 4390 & 5.5 & 2060 & 17.2 & 2.1 & 4.34 \\
\hline $\mathrm{C} 2^{\mathrm{c}}$ & 34.1 & 12,790 & 10.8 & 4050 & 44.9 & 3.2 & 1.91 \\
\hline $\mathrm{C} 3^{\mathrm{c}}$ & 34.0 & 12,750 & 10.6 & 3975 & 44.6 & 3.1 & 4.66 \\
\hline $\mathrm{C} 4^{\mathrm{c}}$ & 23.4 & 8780 & 15.3 & 5740 & 38.7 & 1.5 & 3.76 \\
\hline D1 & 3.9 & 1460 & 2.7 & 1010 & 6.6 & 1.4 & \\
\hline D2 & 3.4 & 1280 & 2.4 & 900 & 5.8 & 1.4 & \\
\hline
\end{tabular}

${ }^{a}$ Isolated yields calculated on the basis of oxygen quantity in batch reactor

${ }^{b}$ Reaction with free radical scavenger 2,6-di-tert-butyl-p-cresol

${ }^{c}$ Suberic acid as by-product is observed (see Fig. 4)

${ }^{\mathrm{d}}$ Mol product $\times$ mol catalyst ${ }^{-1} \times \mathrm{h}^{-1}$

was introduced into the reaction mixture. The catalyst together with the substrate were closed in the air-free autoclave and were heated together with the whole system until temperature of $393 \mathrm{~K}$ was reached. In due time air was added to the hot reaction mixture in such amount that final pressure of $10 \mathrm{~atm}$ was obtained and the reaction started. After $6 \mathrm{~h}$ of reaction time the oxidation was stopped by immersing the hot reactor in a cold water bath. Reaction products (cycloketone and cycloalcohol) were analyzed by means of Agilent Technologies $6890 \mathrm{~N}$ gas chromatograph equipped with Innowax $(30 \mathrm{~m})$ column in the presence of chlorobenzene as internal standard. Amounts of $\mathrm{CO}$ and $\mathrm{CO}_{2}$ were determined chromatographically using PerkinElmer Clarus 500 with methanizer.

The amount of cycloalkane hydroperoxide in the reaction mixture was evaluated by the iodometric titration and Shul'pin method [40-42]. The yield of cycloalkyl hydroperoxide (yield $<0.1 \%$ ) observed after $6 \mathrm{~h}$ of the reaction is too small to have an impact on the results of the subsequent GC analysis.

Stability of catalysts in reaction conditions was tested in the following manner. Compounds $\mathrm{B} 1$ or $\mathrm{C} 2$ were mixed with cyclooctane and boiled $\left(\mathrm{T}_{\mathrm{b}}=149^{\circ} \mathrm{C}\right)$ under reflux (in air) for $24 \mathrm{~h}$. When the mixture was cooled down, catalysts were separated from cyclooctane by filtration and dried in air. Diffraction patterns and IR spectra of fresh catalysts and catalysts after cyclooctane treatment are presented in the Supporting Information (see Fig. SI-11,12 and Fig. SI-13,14).

\subsection{Catalysts Characterization-Crystal Structure Description}

Considering the structural diversity of presented polymolybdates, in particular their dimensionality, the compounds were divided into four main categories. Octamolybdates A1-A3 contain isolated molybdenumoxygen clusters (0-dim). Polymeric materials B1-B4 are built of infinite molybdenum-oxygen chains (1-dim). Compounds $\mathrm{C} 1-\mathrm{C} 4$ are formed by Mo-O layers with amines in between (2-dim). Two types of three-dimensional molybdenum trioxide D1 and D2 represent the last group of compounds (3-dim). The main subject of the presented research was to correlate catalytic activity with the structure of investigated polymolybdates. The number of terminal (oxo) and bridging oxygen atoms $\left(\mu_{\mathrm{n}}\right)$ was also taken into account. In general, all investigated catalysts are $\mathrm{Mo}(\mathrm{VI})$ isopolyoxo compounds, with all Mo atoms in octahedral coordination surrounded only by oxygen or by oxygen and nitrogen atoms.

The basic parameters of the compounds with structure drawings are summarized in Table 1. Main structural features are described below; data for new compounds are highlighted with bold font.

As representatives of isolated (0-dim) compounds we have selected $\gamma$-and $\beta$-octamolybdates of 4-methylpyridine A1- A2, recently investigated by us [39]. These compounds were supplemented by a new $\beta$-octamolybdate of 4-methylanilinium A3 obtained within this study. 
Compounds $\mathrm{A} 1-\mathrm{A} 3$ are built of isolated octamolybdate clusters (0-dim). Eight isomers of octamolybdates are known: $\alpha, \beta, \gamma, \delta, \varepsilon, \zeta, \eta$ and $\theta$. Among them the $\beta$-isomer is the most common, while isomer $\gamma$, considered an intermediate between $\alpha$ and $\beta$ forms is also an important and frequently occurring 'building block' of many polymolybdate structures [52]. Compound A1 is $\gamma$-octamolybdate of 4-methylpyridine. The anion includes 14 terminal oxygen atoms $\left(\mathrm{O}_{\text {oxo }}\right)$ (average $\mathrm{Mo}=\mathrm{O}$ distance is $1.7104(49) \AA), 6$ oxygens $\mu_{2}-\mathrm{O}, 4 \mu_{3}-\mathrm{O}$ and $2 \mu_{4}-\mathrm{O}$. What is more, in A1 complex a molybdenum-nitrogen bond occurs $(\mathrm{Mo}-\mathrm{N}=2.249(2) \AA)$ which is characteristic for this octamolybdate type.

Both $\mathrm{A} 2$ and $\mathrm{A} 3$ are $\beta$-type isomers, where $\mathrm{A} 2$ is octamolybdate of 4-methylpyridine and $\mathrm{A} 3$ is octamolybdate of 4-methylaniline. The arrangement of $\beta$-octamolybdate anion is somewhat different than in the case of A1. The Mo atoms are surrounded only by $\mathrm{O}$ atoms. Each anion includes 14 terminal oxygen atoms (like in the $\gamma$-octamolybdate) average $\mathrm{Mo}=\mathrm{O}$ distance is $1.7007(88) \AA$ in the case of compound A2 and 1.6981(49) $\AA$ for A3), 6 oxygens $\mu_{2}-\mathrm{O}, 4 \mu_{3}-\mathrm{O}$ and $2 \mu_{5}-\mathrm{O}$. The $\beta$ isomer is thermally more stable and more compact than $\gamma$ form. An $\beta$-octamolybdate anion is surrounded by organic cations and molecules of water, connected by a network ofhydrogen bonds. Crystallographic data for A3 is listed in the SI part.

Group of one-dimensional (1-dim) polymeric compounds (with fibrous morphology) consists of compounds B1-B4. Since new compounds B1, B2 turned out to be chemically different, we tested additional compounds belonging to a family of polymeric molybdates. To verify the effect of the type and charge of cation, 1,3phenylenediammonium trimolybdate B3 [45] was selected. To test the effect of organic cation we have undertaken efforts to synthesise trimolybdate of 4-methylaniline (B4). Both B3 and B4 have the same type of anion as B2 but different organic cation (cation charge is $2+$ in the case of $\mathrm{B} 3$ and $1+$ in $\mathrm{B} 4)$.

In the case of B1 the infinite chain (without electric charge) is formed by Mo and $\mathrm{O}$ atoms, with a molecule of 1,2-phenylenediamine (pda) attached to every molybdenum atom. Formally, the compound may be treated as a hybrid molybdenum oxide with the composition of $\mathrm{MoO}_{3}$ (pda). Each of the Mo atoms is coordinated by two nitrogen atoms of pda bringing the coordination number of Mo to 6. In each $\mathrm{MoO}_{4} \mathrm{~N}_{2}$ octahedron two terminal oxygen atoms, in cis relative position, are present, $\mathrm{Mo}=\mathrm{O}_{\text {oxo }}$ bond length is 1.7264(11) $\AA$. Two opposite vertices in each octahedron are occupied by $\mu_{2}-\mathrm{O}$ atoms shared with adjacent octahedra.

New 3,5-dimethylanilinium trimolybdate hydrate (B2) is composed of infinite, anionic chains with $\left(\mathrm{Mo}_{3} \mathrm{O}_{10}\right)_{n}^{2-}$ formula. These rigid, zigzag chains built of distorted octahedra are linked by ionic interactions and hydrogen bonds with 3,5-dimethylanilinium cations. In this compound each $\mathrm{MoO}_{6}$ octahedron contains two terminal oxygen atoms $\left(\mathrm{O}_{\text {oxo }}\right)$ and four $\mu_{3}-\mathrm{O}$ oxygen atoms, that are linking 3 adjacent octahedra. Very similar structure was determined in the case of B4. Crystallographic data for B1, $\mathrm{B} 2$, B4 is listed in SI.

Four pentamolybdates $\mathrm{C} 1-\mathrm{C} 4$ belonging to a group of layered materials (2-dim) have been examined. As a starting point, we selected aniline and 4-methylaniline pentamolybdates $\mathrm{C} 1, \mathrm{C} 2$ [46, 47]. To investigate the influence of substituent, we extended the group of investigated compounds adding pentamolybdate of 4-bromoaniline [48] and a new compound with a larger substituent, that is 4-ethylanilinum pentamolybdate (C4).

All discussed compounds have infinite anionic layers $\left[\left(\mathrm{Mo}_{5} \mathrm{O}_{16}\right)^{2-}\right]_{\mathrm{n}}$, formed by distorted $\mathrm{MoO}_{6}$ octahedra and are surrounded by different cations: $\mathrm{C} 1-$ anilinium, $\mathrm{C} 2$ 4-methylanilinium ( $p$-toluidinium), C3-4-bromoanilinium and $\mathrm{C} 4-4$-ethylanilinium. In the structures of the layered pentamolybdates nearly flat, centro-symmetric blocks of 6 deformed MoO6 octahedra connected by their edges are present. Two boundary octahedra on both sides of each block are common to the two adjacent blocks, so each formal unit consists of $5 \mathrm{MoO}_{6}$ individuals. Two oxygen atoms at a distance of $\sim 1.735 \AA$ are bound to each of the molybdenum atoms. These $\mathrm{O}$ atoms are always in cis position relative to each other. The $\left(\mathrm{Mo}_{5} \mathrm{O}_{16}\right)^{2-}$ anion contains 10 oxygen atoms of this type, among them 6 are terminal atoms, wherein 4 are perpendicular to the plane of the layers. Each of the remaining four, strongly bonded oxygen atoms are common for two coordination polyhedra of neighbouring $\mathrm{Mo}_{\mathrm{n}}$ and $\mathrm{Mo}_{\mathrm{n}}$, atoms $\left(\mathrm{Mo}_{\mathrm{n}} \mathrm{O} \sim 1.70 \AA\right.$, $\mathrm{O}-\mathrm{Mo}_{\mathrm{n}}, \sim 2.42$ to $2.74 \AA$ ). Octahedral coordination of four Mo atoms in each pentamolybdate unit is achieved through an oxygen atom placed at a long distance of $\sim 2.4$ to $2.7 \AA$ from Mo atom. We believe that the fragment: $\mathrm{Mo}_{\mathrm{n}}{ }^{-}$ $\mathrm{O}_{\mathrm{m}} \ldots \mathrm{Mo}_{\mathrm{n}}$, (where $\mathrm{Mo}_{\mathrm{n}}-\mathrm{O}_{\mathrm{m}} \sim 1.74 \AA$, $\measuredangle \mathrm{Mo}_{\mathrm{n}}-\mathrm{O}_{\mathrm{m}} \ldots \mathrm{Mo}_{\mathrm{n}}$, $\sim 165^{\circ}, \mathrm{O}_{\mathrm{m}}-\mathrm{Mo}_{\mathrm{n}}, \sim 2.60 \AA$ ) is a characteristic feature of pentamolybdates. In $\left(\mathrm{Mo}_{5} \mathrm{O}_{16}\right)^{2-}$ unit $6 \mu_{2}-\mathrm{O}$ and $4 \mu_{3}-\mathrm{O}$ atoms are present (see Fig. 1 and SI for details for $\mathrm{C} 4$ ).

Three-dimensional hexagonal molybdenum trioxide D1 (3-dim) forms a system of parallel channels with a diameter of $\sim 5.8 \AA$, which allows penetration of the channels by monovalent ions $\left(\mathrm{H}^{+}, \mathrm{Ag}^{+}, \mathrm{K}^{+}, \mathrm{Rb}^{+}\right.$, etc.) [49]. For comparison purposes, we have also tested $\mathrm{D} 2$, a commercially available orthorhombic $\mathrm{MoO}_{3}$ ( $\mathrm{POCh}$ Gliwice). It is a layered compound with the distance between thick double layers of about $6.5 \AA$, whereas the distances between atoms from adjacent layers, interacting through van der Waals forces, are about 2.9 to $3.5 \AA$ [50]. 


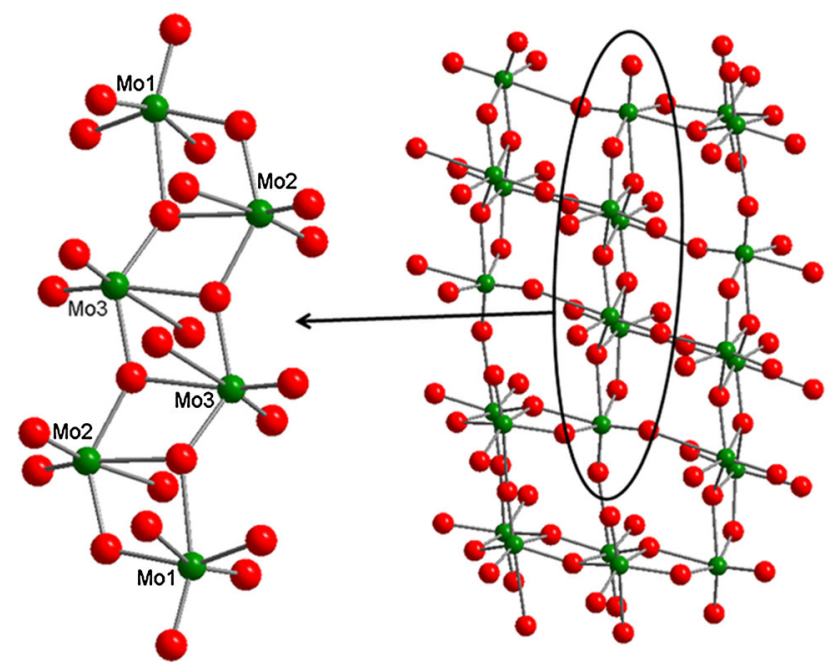

Fig. 1 Pentamolybdate building block and infinite layer, view along a axis

\section{Catalytic Results}

Three different cycloalkanes, viz. cyclopentane, cyclohexane or cyclooctane were applied as substrates (Scheme 1) with molybdenum complex B2 as a representative catalyst.

The main products of cycloalkanes oxidation with molecular oxygen (from air) were cycloketone and cycloalcohol. No oxidation occurred at $393 \mathrm{~K}$ in the absence of the catalyst. For cyclopentane, only $2.9 \%$ yield of ketone $(\mathrm{TON}=1090)$ and $0.8 \%$ yield of alcohol (TON $=300)$ was obtained in the presence of Mo catalyst B2 after 6 h (Fig. 2). Under analogous conditions, cyclohexane was converted to ketone and alcohol with yields of $5.2 \%(\mathrm{TON}=1950)$ and $2.2 \%(\mathrm{TON}=830)$, respectively. Finally, the oxidation of cyclooctane catalyzed by B2 resulted in $29.6 \%$ yield for ketone $(\mathrm{TON}=11,100)$ and $15.5 \%$ yield for alcohol $(\mathrm{TON}=5812)$.

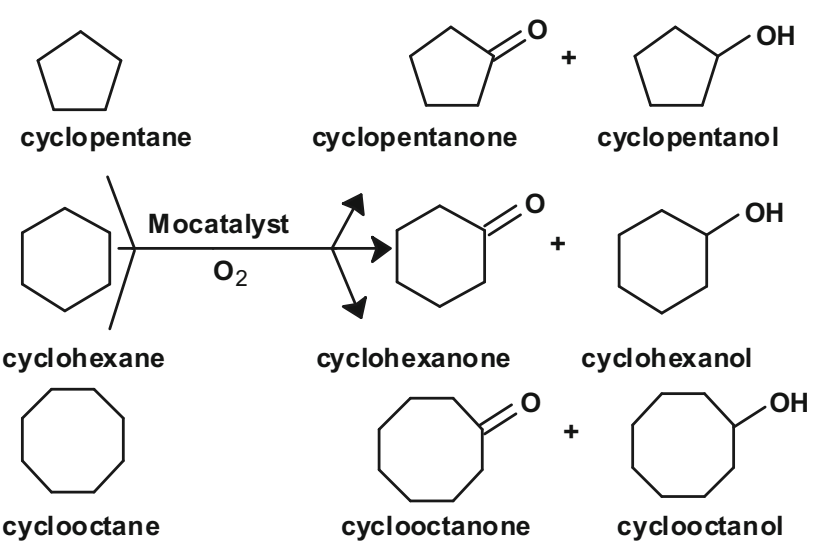

Scheme 1 Oxidation of cycloalkanes

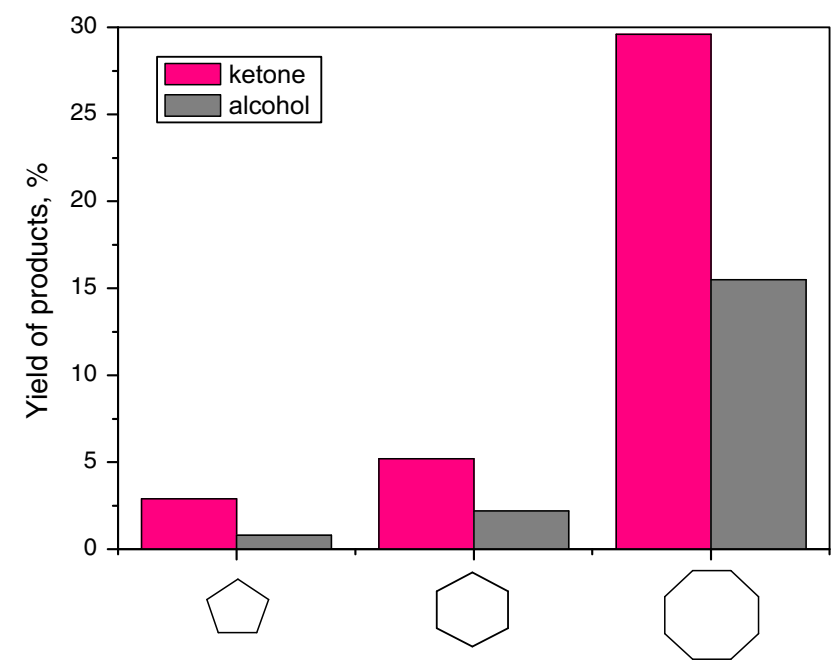

Fig. 2 Oxidation of different cycloalkanes by Mo catalyst $\mathbf{B 2}$

Cyclooctane was determined to be the most reactive of all investigated cycloalkanes and the following order of catalytic reactivity was established: cyclooctane $>$ cyclohexane $>$ cyclopentane. Consequently, cyclooctane was selected for further investigations. All the catalytic results of cyclooctane oxidation with molecular oxygen are gathered in Table 2 and presented in Figs. 2 and 3. All applied polyoxomolybdates were active as catalysts in the oxidation of cyclooctane.

The A1-A3 compounds (0-dim) built of isolated octamolybdate anions show moderate activity towards desired products. All compounds demonstrate quite similar selectivity towards ketone but A2 reaches only $50 \%$ of selectivity towards alcohol in comparison with two other members of the series.

Compounds of the B series (1-dim) demonstrate high catalytic activity. Compound B1 shows the highest catalytic activity among all the studied catalysts. The

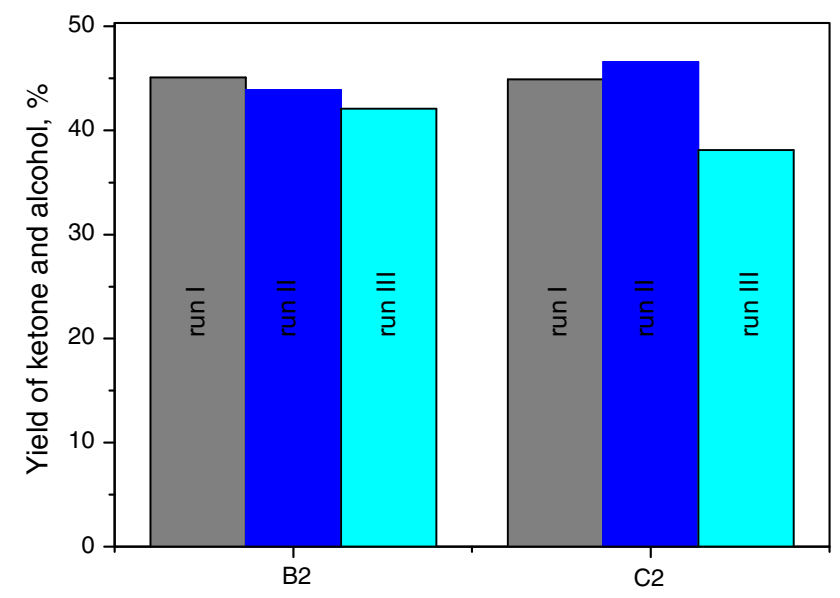

Fig. 3 Recycling and reuse of B2 and C2 molybdenum catalysts 
following order of catalytic activity was established: $\mathrm{B} 1>\mathrm{B} 3>\mathrm{B} 2 \geq \mathrm{B} 4$. B2 was twice recovered from the reaction mixture and reused in the catalytic reaction. Yield of ketone and alcohol decreases insignificantly in the subsequent runs which is important for the possibility of recycling and reuse of molybdenum catalysts (Fig. 3). Higher catalytic activity of B3 in comparison with B2 and B4 catalysts is intriguing taking into account the identical polymeric structure of the trimolybdate anion.

Layered compounds: C1-C4 (2-dim) demonstrate diverse catalytic activity (Fig. 4). C2 and C3 pentamolybdates show similar catalytic activity and selectivity towards the desired products. For $\mathrm{C} 4$ the selectivity to ketone slightly decreases while selectivity to alcohol increases significantly in comparison to $\mathrm{C} 2$ and $\mathrm{C} 3$ catalysts. C2 catalyst was recycled and reused with only a small change of catalytic activity (Fig. 3) preserving the original crystal structure as indicated by XRPD studies.

It is important to state that for the whole series of C catalysts an additional product, suberic acid, was identified. Its formation is connected with the presence of cycloalcoxy radical formed during the oxidation of cyclooctane (Scheme 2) and stabilized between layers of C catalysts. The formation of suberic acid was found by XRPD analysis of the solid phase left in the batch reactor after the oxidation reaction with layered $\mathrm{C} 1-\mathrm{C} 4$ catalysts.

Considering the surface area values for compounds $\mathrm{C} 1-$ $\mathrm{C} 4$, one can see that they are rather small, and it appears that surface is not the main factor determining catalytic activity (Table 2). For example in case of $\mathrm{C} 1$ the biggest surface area was determined, whereas it is the worst catalyst in Cn family; exactly the opposite observation can be made in the case of $\mathrm{C} 2$. Similar observation can be made in case of compounds from B series.

Molybdenum oxides: hexagonal molybdenum oxide D1 and orthorhombic $\mathrm{MoO}_{3}$ D2 show the lowest catalytic activity among the tested catalysts. Low availability of molybdenum-oxygen catalytic centres and a system of

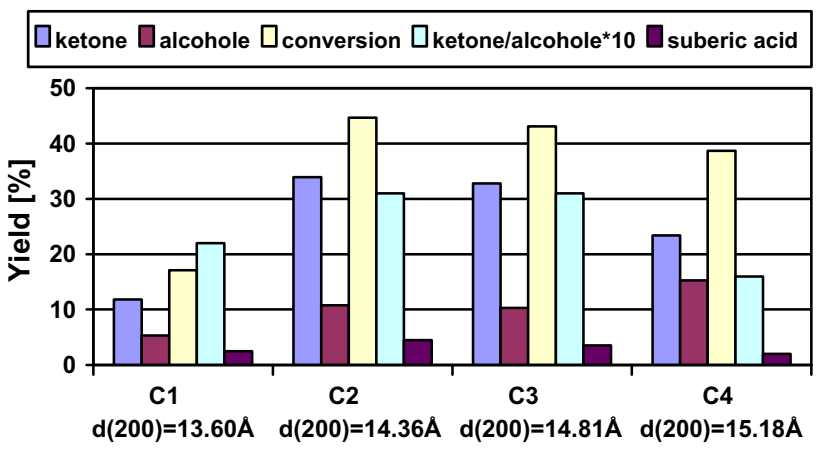

Fig. 4 Oxidation of cyclooctane with layered $\mathrm{C} 1-\mathrm{C} 4$ compounds. In the lowest row interplanar $\mathrm{d}(200)$ spacings are given. Conversion indicates yield of ketone + alcohole narrow channels in three-dimensional covalent structure that may be too small for the reactants to enter into, seem to be the reason behind such poor results.

Summarizing, the best catalytic performance for oxidation of cyclooctane was observed for the polymeric B1, B3 and layered C2, C3 materials. The results obtained indicate that the catalytic activity is not only dependent on the structure of the inorganic anion, but also on other factors, e.g. type of organic cation and its charge, crystal structure etc.

\section{Discussion}

Structural differences between the $\beta$ and $\gamma$-octamolybdate anions are relatively small (the same amount of oxo oxygens, and $\mu_{2}-\mathrm{O}$ atoms), which may explain quite similar catalytic activity. Slightly higher activity is observed for $\gamma$ octamolybdate A1 in which 2 nitrogen atoms are directly connected to Mo atoms. Also, in the case of $\gamma$-octamolybdates average $\mathrm{Mo}=\mathrm{O}$ distance is slightly longer than in the case of $\beta$-octamolybdates. The presence of nitrogen atoms directly connected to Mo atoms, which is also observed in one of the most active B1 catalyst, seems to be a factor contributing to a higher catalytic activity. However, the high activity of B3, C2, C3 (without Mo-N bonds) proves the existence of additional factors needed to be taken into account when discussing catalytic activity.

A very interesting observation is the high conversion of cyclooctane for hybrid polymeric molybdenum oxide B1. It seems that organic part of the compound improves liofility (wettability), whereas rigid inorganic-chain ensures the availability of catalytic centers (of yet unknown type) along the polymeric chain. In comparison, anionic polymeric core in typical trimolybdates reduces the availability of catalytic centers along one-dimensional chain, by the presence of cations compensating its negative charge. This may be an explanation of the much lower activity of B2 and B4 in comparison to B1. These assumptions are confirmed by high activity of the compound B3 (with exactly the same polymeric anion as in $\mathrm{B} 2$ and $\mathrm{B} 4$ ). In this case $\left[\mathrm{NH}_{3}-\mathrm{C}_{6} \mathrm{H}_{4}-\mathrm{NH}_{3}\right]^{2+}$ cations are present, and the number of these cations needed to neutralize the charge of anionic chain is halved with respect to B2 or B4. In this way the availability of the active centers increases by providing "free space" along anionic chain unoccupied by the cations.

The high conversion of cyclooctane for $\mathrm{C} 2$ and $\mathrm{C} 3$ and its significantly higher value compared to $\mathrm{C} 1$ is surprising due to high similarity in chemical composition, structure of the anion and location and arrangement of the cations. Steric reasons may give a clue. For the reaction to proceed, cyclooctane molecules must be absorbed in the inter-layer 
Scheme 2 Mechanism of cycloalkanes oxidation in the presence of polymolybdates catalysts
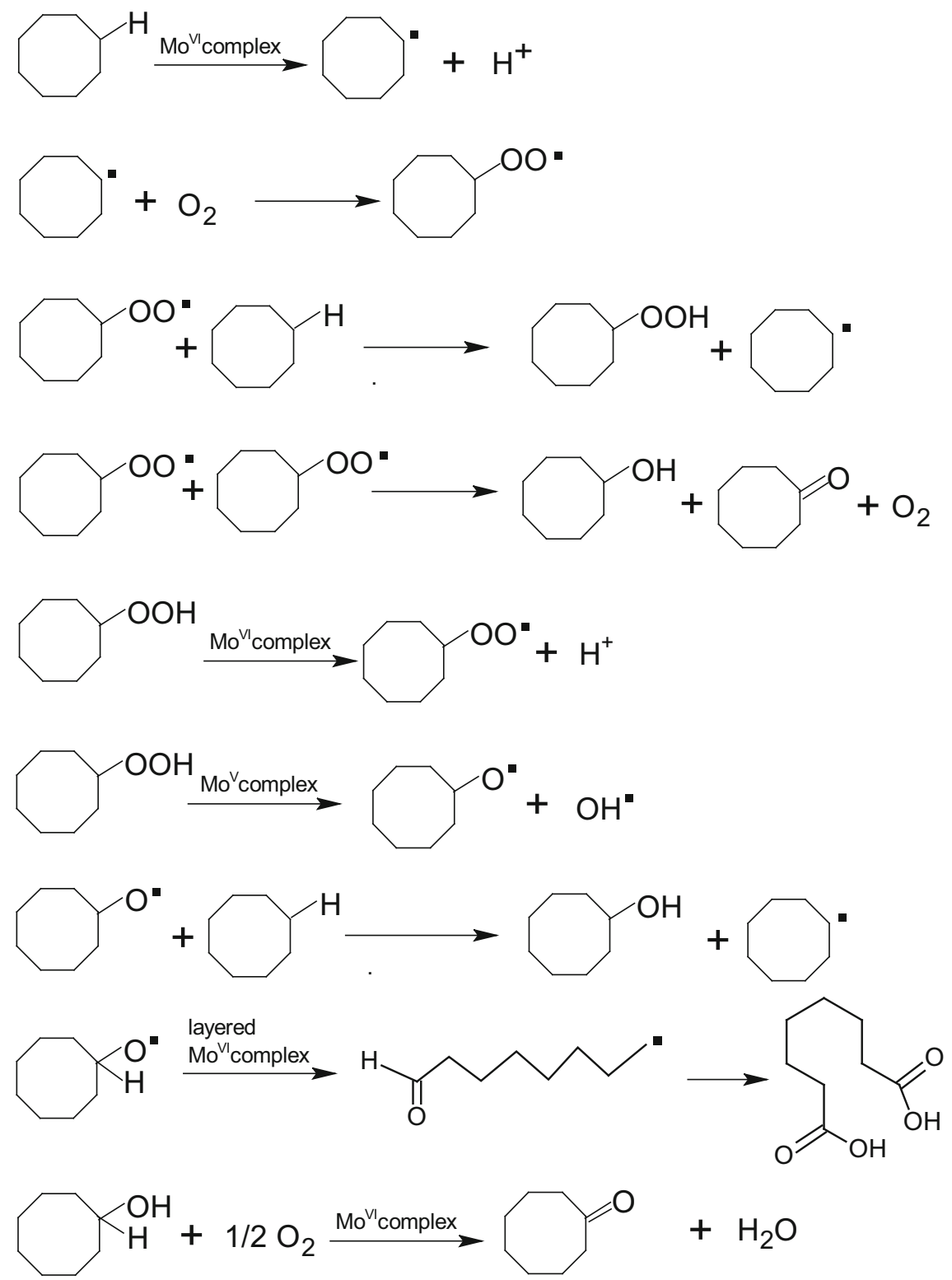

space of pentamolybdates. Cyclooctane seems to require slightly more space than anilinium ion can provide, hence the low activity of the compound $\mathrm{C} 1$. Further, more detailed considerations included the examination of the impact of the distances between the layers on the catalytic activity. The yield of products for 4-methylanilinium pentamolybdate $\mathrm{C} 2 \quad[\mathrm{~d}(200)=14.36 \AA]$ and 4-bromoanilinium pentamolybdate $\mathrm{C} 3[\mathrm{~d}(200)=14.81 \AA]$ is similar. Figure 4 shows that there is an optimal distance between layers [corresponding to the inter-planar spacing $\mathrm{d}(200)$ ] for the best catalytic performance. If the interlayer distance is too small, like in $\mathrm{C} 1[\mathrm{~d}(200)=13.6 \AA]$, the oxidation reaction is more difficult to proceed and the formation of oxidation products (along with suberic acid) is suppressed. Increasing the distance between layers above the optimal size does not provide a clear benefit. It may even result in a decrease in catalytic activity, as is revealed for the $\mathrm{C} 4$ compound for which the distance $\mathrm{d}(200)=15.18 \AA$ A. Interplanar $\mathrm{d}(200)$ spacings used in Fig. 4 are derived from lattice constants and formulas of geometric crystallography. This value gives an estimation of space available between neighbouring layers in catalyst. Based on the yields of obtained products, correlation existing between $\mathrm{d}(200)$ and catalytic performance for very 
similar compounds $(\mathrm{C} 1-\mathrm{C} 4)$ seems to be reasonable and justified.

Pentamolybdate layers are open-framework constructions with variable thickness, which may allow for the oxygen to pass through the layers. Adsorbed molecule trapped in the oxidizing environment, may undergo further oxidation reactions leading to formation of suberic acid. For compounds A1-A3 (0-dim) or polymeric B1-B4 (1$\operatorname{dim}$ ), after the occurrence of a single process of oxidation, molecules of cyclooctanone or cyclooctanol can easily drift away from the catalyst surface through diffusion. In a qualitative manner, this also explains the lower ratio of ketone/alcohol for these catalysts (see Table 2), and the lack of suberic acid in the reaction products.

Oxidation of alkanes was widely studied by many researchers. Oxidation of cyclohexane and cyclooctane with hydrogen peroxide as oxygen donor was performed in the presence of the $\mathrm{CH}_{3} \mathrm{ReO}_{3}$-PCA system. Formation of the cycloalkyl hydroperoxide, which was the main product in the cycloalkane oxidation, proceeded via free-radical mechanism [36].

Radical mechanism of cyclooctane oxidation was also observed for the reaction performed with $\mathrm{H}_{2} \mathrm{O}_{2}$ at low temperature [41, 42]. In contrast to our catalytic system, cyclooctyl hydroperoxide was the main reaction product.

Non-radical reaction mechanism of cycloalkane oxidation was described by [53] using t-butyl hydroperoxide and peracetic acid as oxygen donors and ruthenium catalyst. The reaction proceeds through the oxo-ruthenium species. In this case the reaction was carried out in the presence of radical sacavenger.

Similar catalytic systems based on polyoxometalates as catalysts were studied in the cyclooctane oxidation with molecular oxygen [54]. Introduction of cobalt ion into heteropoly structure significantly influences the catalytic activity and selectivity in the studied reaction. The amount of cyclooctyl hydroperoxide formed during the reaction was negligible.

Salen metallocomplexes were also investigated in the same reaction conditions [55]. Catalytic activities of salen complexes and polymolybdates are similar, selectivity to cycloketone is different, though.

Based on the literature [56-61] and our investigations, we suggest the following oxidation mechanism in the presence of polymolybdate catalysts (Scheme 2).

According to Sheldon and Kochi [56] the oxidation of cycloalkanes with molecular oxygen proceeds via freeradical mechanism. The radical chain reaction mechanism of this reaction was experimentally confirmed by us, showing almost complete inhibition of cyclooctane oxidation in the presence of a free radical scavenger 2,6-di-tertbutyl-p-cresol (DBPC).
A hypothetical set of reactions is presented in Scheme 2. Except cycloketone and cycloalcohol, which are the major products of this reaction, small amounts of cyclohydroperoxide are observed but the formation of ring-opened side-products like di-carboxylic acids is also possible through this mechanism. It is well-known that the selective catalytic oxidation of $\mathrm{C}-\mathrm{H}$ bonds results in the formation of hydroperoxides [36-38]. For the investigated polymolybdates only traces of hydroperoxide $(<0.1 \%)$ were detected after $6 \mathrm{~h}$ of reaction which is indicative of polymolybdates as good catalysts for hydroperoxides decomposition.

The first step of the whole process is a slow reaction of the cycloalkane with polymolybdate resulting in the abstraction of hydrogen from hydrocarbon to form cycloalkyl radical $\mathrm{R}^{\bullet}$ (Reaction 1 ), which acts as the initiation of chain reaction [57-59]. The newly formed species can react further with molecular oxygen in the chainpropagation step to the cycloperoxyl radical $\mathrm{ROO}^{\bullet}$ (Reaction 2). This in turn reacting with cycloalkane gives cyclohydroperoxide $\mathrm{ROOH}$ and cycloalkyl radical $\mathrm{R}^{\bullet}$ (Reaction 3). Recombination of cycloperoxyl radicals $\mathrm{ROO}^{\circ}$ is a first source of cycloketone and cycloalcohol constituting the major chain-termination step (Reaction 4). Cyclohydroperoxide can be decomposed in a heterolytic $[56,60]$ or homolytic $[56,61]$ manner. The heterolytic decomposition of cyclohydroperoxide catalyzed by molybdenum catalyst produces cycloperoxyl radical $\mathrm{ROO}^{\bullet}\left(\right.$ Reaction 5) while cycloalkoxyl radical $\mathrm{RO}^{\bullet}$ and hydroxyl radical $\mathrm{OH}^{\bullet}$ are produced in homolytic decomposition (Reaction 6). Majority of cycloalcohol is produced in Reaction 4. Additional amount of cycloalcohol originates from abstraction of hydrogen from cycloalkane by cycloalkoxyl radical (Reaction 7). Cycloalkoxyl radicals can also undergo a $\beta$-cleavage of $\mathrm{C}-\mathrm{C}$ bond [62-65] yielding the ring-opened $\omega$-formyl radical $\mathrm{CHO}-(\mathrm{CH} 2) 6-$ $\mathrm{CH} 2$ which is the precursor for obtaining di-carboxylic acid (Reaction 8). However, the literature dealing with cycloalkane oxidation claims that cycloketone is the most important precursor of ring-opened by-products [56-61]. In all our catalytic tests the yield of cycloketone is higher than the yield of cycloalcohol. This is a clear indication that cycloketone can be formed not only in Reaction 4 but also in the oxidation of the cycloalcohol (Reaction 9).

To sum up the discussion, we have to consider all the data which characterize the investigated compounds (also data gathered in SI). In particular:

- Formation of $\mathrm{CO}$ and $\mathrm{CO}_{2}$ is not observed during the oxidation of cycloalkanes.

- Stability of compounds in reaction conditions was indicated by XRPD studies versus temperature (see Supporting Information). 
- Recoverability and reusability of catalysts (B2, C2) with only a small change of catalytic activity of fresh and spent samples were confirmed (Fig. 3).

- Compounds B1 and $\mathrm{C} 2$ boiled in cyclooctane $\left(\mathrm{T}_{\mathrm{b}}\right.$ higher than the temperature of reaction) remain unchanged (see Supporting Information). Furthermore, compounds of $\mathrm{C}$ series were synthesized from the reaction mixture containing boiling water solution $(\mathrm{pH}$ 2 ). Since the catalysts were synthesized in rather severe conditions, their solubility in cycloalkane in given reaction conditions is doubtful.

- Rather obvious dependence of catalytic activity on cationic charge in compounds B2-B4 was observed.

- Dependence of catalytic properties on interplanar $\mathrm{d}(200)$ spacing in the case of $\mathrm{C} 1-\mathrm{C} 4$ was demonstrated.

- Low surface area for all the investigated compounds and no obvious correlation between surface and catalytic activity indicate the significance of factors other than the surface area.

All these observations allow us to draw a final conclusion that the crystal structures of the catalysts investigated by us are important factors in the catalytic process. This also supports the heterogeneous character of the catalytic reaction, at least in the case of the most stable $\mathrm{B} 1, \mathrm{~B} 3, \mathrm{C} 1-$ C4 catalysts.

\section{Conclusions}

The first example of oxidation reaction of cycloalkanes with molecular oxygen without solvent and co-reductor that involves polymolybdate complexes as catalysts is reported.

Polymolybdates with anions in the form of isolated clusters A (0-dim), compounds with polymeric anions B (1-dim), layered materials $\mathbf{C}$ (2-dim) as well as hexagonal and orthorhombic molybdenum oxides D (3dim) were selected, synthesized and physico-chemically characterized (if needed) and applied in the process of catalytic oxidation of cycloalkanes. Among them A3, B1, B2, B4, C4 polymolybdates were synthesized for the first time.

All the synthesized compounds were active in the investigated reaction. For series of $\mathbf{B}$ and $\mathbf{C}$ catalysts high catalytic activity was observed. Moreover, for the series of layered $\mathbf{C}$ catalysts the oxidation of cyclooctane to cyclooctanone and cyclooctanol is accompanied by the formation of suberic acid $(\mathrm{COOH})-\mathrm{C}_{6} \mathrm{H}_{12}-(\mathrm{COOH})$. Formation of suberic acid is observed for layered polymolybdates only. Product yields for $\mathbf{C}$ series seem to be affected by inter-layer distance between $\left[\mathrm{Mo}_{5} \mathrm{O}_{16}\right]_{n}^{2-}$ anions.
The most active compounds B1, B3, C2, C3 are stable up to about $200{ }^{\circ} \mathrm{C}$ (temperature dependent XRPD, see Supporting Information). What is more, catalysts are recoverable and reusable, which indicates the possibility of practical applications.

The catalytic properties of these materials are complex features resulting from their crystal structure and chemical composition. The interesting catalytic activity can be observed for one-dimensional (polymeric) or two dimensional (layered) materials. For the layered materials the highest catalytic activity is obtained after adjusting proper, optimal distance between layers. For the anionic polymers B2, B4 higher blocking of molybdenum catalytic centers (by cations) decreases the activity of the catalyst.

Acknowledgments The research has been partly supported by the EU Human Capital Operation Program, Polish Project No. POKL.04.0101-00-434/08-00. The research was carried out with the equipment purchased thanks to the financial support of the European Regional Development Fund in the framework of the Polish Innovation Economy Operational Program (contract no. POIG.02.01.0012-023/08). The authors also wish to acknowledge the synchrotron centres: DIAMOND and DESY for diffraction measurements. CCDC-1041613, 909664, 1042866, 1042865, 1041614 contain the supplementary crystallographic data for compounds A3, B1, B2, B4, C4, respectively. These data can be obtained free of charge from The Cambridge Crystallographic Data Centre via www.ccdc.cam.ac.uk/ data_request/cif.

Open Access This article is distributed under the terms of the Creative Commons Attribution 4.0 International License (http://crea tivecommons.org/licenses/by/4.0/), which permits unrestricted use, distribution, and reproduction in any medium, provided you give appropriate credit to the original author(s) and the source, provide a link to the Creative Commons license, and indicate if changes were made.

\section{References}

1. Enemark JH, Cooney JJA, Wang J-J, Holm RH (2004) Chem Rev 104:1175-1200

2. Lyashenko G, Saischek G, Judmaier ME, Volpe M, Baumgartner J, Belaj F, Jancik V, Herbst-Irmer R, Mösch-Zanetti NC (2009) Dalton Trans 29:5655-5665

3. Yin GC (2010) Coord Chem Rev 254:1826-1842

4. Hille R, Hall J, Basu P (2014) Chem Rev 114:3963-4038

5. Cindrić M, Novak TK, Krajlević S, Krajl M, Kamenar B (2006) Inorg Chim Acta 359:1673-1680

6. Cartuyvels E, Van Hecke K, Van Meervelt L, Görller-Walrand C, Parac-Vogt TN (2008) J Inorg Biochem 102:1589-1598

7. Cindrić M, Veksli Z, Kamenar B (2009) Croat Chem Acta 82(2):345-362

8. Djordjevic C, Puryear BC, Vuletic N, Abelt CJ, Sheffield SJ (1988) Inorg Chem 27:2926-2932

9. Dickman MH, Pope MT (1994) Chem Rev 94:569-584

10. Thiel WR (1997) J Mol Catal A: Chem 117:449-454

11. Jia M, Thiel WR (2002) Chem Commun 20:2392-2393

12. Pereira CCL, Balula SS, AlmeidaPaz FA, Valente AA, Pillinger M, Klinowski J, Goncalves IS (2007) Inorg Chem 46:8508-8510 
13. Brito JA, Teruel H, Muller G, Massou S, Gomez M (2008) Inorg Chim Acta 361:2740-2746

14. Abrantes M, Amarante TR, Antunes MM, Gago S, Paz FAA, Margiolaki I, Rod-rigues AE, Pillinger M, Valente AA, Goncalves IS (2010) Inorg Chem 49:6865-6873

15. Pisk J, Agustin D, Vrdoljak V, Poli R (2011) Adv Synth Catal 353:2910-2914

16. Pisk J, Prugovecki B, Matkovic-Calogovic D, Poli R, Agustin D, Vrdoljak V (2012) Polyhedron 33:441-449

17. Amarante TR, Neves P, AlmeidaPaz FA, Pillinger M (2012) AA Valente. I Inorg Chem Comm 20:147-152

18. Rayati S, Rafiee N, Wojtczak A (2012) Inorg Chim Acta 386:27-35

19. Masteri-Frhani M, Kashef Z (2012) J Magn Magn Mater 324:1431-1434

20. Grivani G, Akherati A (2013) Inorg Chem Comm 18:90-93

21. Djordjevic C, Puryear BC, Vuletic N, Abelt CJ, Sheffield SJ (1997) Inorg Chem 36:1798-1805

22. Das S, Bhowmick T, Punni-Yamurthy T, Dey D, Nath J, Chaudhuri MK (2003) Tetrahedron Lett 44:4915-4917

23. Gharah N, Chakraborty S, Mukherjee AK, Bhattacharyya R (2004) Chem. Comm. 22:2630-2632

24. Bregeault J-M, Vennant M, Salles L, Piquemal J-Y, Mahha Y, Briot E, Baka-la PC, Atlamsani A, Thouvenot R (2006) J Mol Catal A Chem 250:177-189

25. Mancka M, Plass W (2007) Inorg Chem Commun 10:677-680

26. Gharah N, Chakraborty S, Mukherjee AK, Bhattacharyya R (2009) Inorg Chim Acta 362:1089-1100

27. Madeira F, Barroso S, Namorado S, Reis PM, Royo B, Martinsm AM (2012) Inorg. Chim Acta 83:152-156

28. Bagherzadeh M, Amini M, Parastar H, Jalali-Heravi M, Ellern AA, KeithWoo L (2012) Inorg Chem Commun 20:86-89

29. Carrasco CJ, Montilla F, Alvarez E, Herbert M, Galindo A (2013) Polyhedron 54:123-130

30. Sensato FR, Custodio R, Longo E, Safont VS, Andres J (2003) J Org Chem 68:5870-5874

31. Pontes da Costa A, Reis PM, Gamelas C, Romao CC, Royo B (2008) Inorg Chim Acta 361:1915-1921

32. Bagherzadeh M, Tahsini L, Latifi R, Ellern A, KeithWoo L (2008) Inorg Chim Acta 361:2019-2024

33. Bagherzadeh M, Mehdi Haghdoost M, Amini M, Derakhshandeh PG (2012) Catal Commun 23:14-19

34. Bagherzadeh M, Amini M, Ellern A, KeithWoo L (2012) Inorg Chem Commun 15:52-55

35. Herrmann WA, Lobmaier GM, Priermeier T, Mattner MR, Scharbert B (1997) J Mol Catal A Chem 117:455-469

36. Shulpin GB (2002) J Mol Catal A Chem 189:39-66

37. Połtowicz J, Haber J (2006) J Mol Catal A Chem 250:177-189

38. Duprez D, Cavani F (2014) Handbook of advanced methods and processes in oxidation catalysis. Imperial College Press, London, pp 320-333
39. Szymańska A, Nitek W, Mucha D, Karcz R, Pamin K, Połtowicz J, Łasocha W (2013) Polyhedron 60:39-46

40. Mair RD, Graupner AJ (1964) Anal Chem 36:194-204

41. Shulpin GB, Kozlov YN, Shulpina LS, Kudinov AR, Mandelli D (2009) Inorg Chem 48:10480-10482

42. Shulpin GB, Kozlov YN, Shulpina LS, Petrovskiy PV (2010) Appl Organometal Chem 24:464-472

43. Szymańska A, Nitek W, Rutkowska-Żbik D, Łasocha W (2014) Monatsh Chem 145:921-929

44. Román P, Gutiérrez-Zorrilla JM, Martínez-Ripoll M, GarcíaBlanco S, Cryst J (1987) Spectrosc. 17:109-119

45. Łasocha W, Rafalska-Łasocha A, Grzywa M, Gaweł B (2008) Catal Today 137:504-509

46. Łasocha W, Schenk H (1997) J Appl Cryst 30:909-914

47. Oszajca M, Smrcok L, Łasocha W (2013) Acta Cryst 69:1367-1372

48. Łasocha W, Grzywa M, Oszajca M, Kristallogr Z (2009) Suppl 30:387-394

49. Guo J, Zavalij P, Whittingham M (1994) Eur. J. Sol. State Inor. $31: 833$

50. Gruber H, Krautz E (1980) Phys Status Solidi A 62:615

51. Brandenburg K, Putz H, Diamond: crystal and molecular structure visualization crystal impact. GbR, Postfach 1251. D-53003 Bonn

52. Allis DG, Rarig RS, Burkholder E, Zubieta J (2004) J Mol Struct 688:11-31

53. Murahashi Sh-I, Komiya N, Oda Y, Kuwabara T, Naota T (2000) J Org Chem 65:9186-9193

54. Pamin K, Jachimska B, Onik K, Połtowicz J, Grabowski R (2009) Catal Lett 127:167-174

55. Połtowicz J, Pamin K, Tabor E, Haber J, Adamski A, Sojka Z (2006) Appl Catal A 299:235-242

56. Sheldon RA, Kochi JK (1981) Metal catalyzed oxidations of organic compounds. Academic Press, London, pp 34-70

57. Hermans I, Jacobs PA, Peeters J (2006) J Mol Catal A: Chem 251:221-228

58. Mishra GS, Frausto de Silva JJR, Pombeiro AJL (2007) J Mol Catal A Chem 265:59-69

59. Hermans I, Peeters J, Jacobs PA (2008) Top Catal 48:41-48

60. Traylor TG (1987) Feng Xu. J Am Chem Soc 109:6201-6202

61. Mansuy D, Bartoli J-F, Momenteau M (1982) Tetrahedron Lett 23:2781-2784

62. Barclay LRC, Lusztyk J, Ingold KU (1984) J Am Chem Soc 106:1793-1796

63. Druliner JD, Krusic PJ, Lehr GF, Tolman CA (1985) J Org Chem 50:5838-5845

64. Beckwith ALJ, Hay BP (1989) J Am Chem Soc 111:230-234

65. Olivella S, Sole A (1991) J Am Chem Soc 113:87-94 